\title{
Commentary: The moral bioenhancement of psychopaths
}

\author{
Elisabetta Sirgiovanni ${ }^{1 *}$ and Mirko Daniel Garasic ${ }^{2}$ \\ ${ }^{1}$ Department of Molecular Medicine, Faculty of Pharmacy and Medicine, Sapienza University of Rome, Rome, Italy, ${ }^{2}$ Libera \\ Università Maria SS. Assunta, Rome, Italy
}

Keywords: moral bioenhancement, psychopathy, consent and refusal to treatment, involuntary treatment, open justification

\section{A Commentary on}

The moral bioenhancement of psychopaths

by Baccarini E., and Malatesti L. (2017). J. Med. Ethics 43, 697-701. doi: 10.1136/medethics-2016-103537

Baccarini and Malatesti (2017) defend the idea that we must use coercively biomedical means to enhance the morality of a specific group of individuals: psychopaths, diagnosed through the Psychopathy Checklist-Revised (PCL-R) standards (Hare, 2003). Their argument is theoretical, thus it goes independently from the actual effectiveness of existent treatments, and it is based on a logical reasoning. Moral bioenhancement (MB) means include psychotropic drugs, brain stimulations, neurosurgeries, genetic editing, etc.

In short, the authors apply Gerald Gaus' account of open justification (Gaus, 1996, 2011),

OPEN ACCESS

Edited by:

José M. Muñoz,

Universidad Europea de

Valencia, Spain

Reviewed by:

Ezequiel Norberto Mercurio, University of Buenos Aires, Argentina

*Correspondence:

Elisabetta Sirgiovanni elisabetta.sirgiovanni@uniroma1.it

Specialty section: This article was submitted to Theoretical and Philosophical Psychology, a section of the journal

Frontiers in Psychology

Received: 19 August 2019 Accepted: 04 December 2019 Published: 08 January 2020

Citation: Sirgiovanni E and Garasic MD (2020) Commentary: The moral bioenhancement of psychopaths. Front. Psychol. 10:2880 doi: 10.3389/fpsyg.2019.02880 according to which "a prescription addressed to an agent is a reasoning that includes premises that consider the system of reasons (such as beliefs, preferences, etc.) of that agent" (Baccarini and Malatesti, 2017, p. 1). In their view, coercive MB of psychopaths is morally sound and deducible by reasons within the psychopath's cognitive-affective system-even if the psychopath needs not to be able to consciously or sincerely endorse them.

Notoriously psychopaths have Machiavellian traits, a dimension in the Dark Triad (Paulhus and Williams, 2002), including anti-sociality and narcissism. In order to exploit others, the psychopath wishes to live in a society where everyone is cooperative except herself. Consequentially, the psychopath would prescribe MB to other psychopaths. The authors state that an agent must apply to herself a prescription she would accept for others, "if she shares with them the relevant characteristics" (i.e., psychopathic traits), and "unless (s)he can justify to others that the two cases are relevantly different" (Baccarini and Malatesti, 2017, p. 3). Since the psychopath possesses the same personality traits of other psychopaths, the authors claim we would be justified, in Kantian terms, to universalize the prescription of mandatory $\mathrm{MB}$ to her.

We believe that this argument is flawed. In sum, we argue that the psychopath's cognitive-affective system would consistently justify reasons against mandatory MB to herself, even if she wishes differently for others, and that the prescription cannot be extended. What "immoral rule" is the best deducible from the psychopath's cognitive-affective system? If we think of human morality as cooperation in evolutionary terms (Curry, 2016), as the authors do, it seems that psychopaths contradict what has been held inter-culturally as a guiding principle of reciprocity, the Golden Rule. On the contrary, psychopaths respond to what we may call, from the triad, a Dark Rule. Psychopaths believe and feel that "one can treat others (i.e., manipulating, hurting, torturing, killing, etc.) in ways that one would not like to be treated." In fact, there is no evidence that psychopaths wish to be treated (even unconsciously) in the same ways they treat others. Research shows that when viewing stimuli depicting bodily injuries adopting an image-self perspective, psychopaths 
have normal neural responses for pain (Decety et al., 2013). These responses do not match the atypical patterns of brain activation psychopaths show when adopting an other-perspective. Thus, the psychopath can consistently justify within her cognitive-affective system that her own case and the other psychopaths' case are relevantly different.

It could be objected that a Dark Rule entails for the psychopaths to accept to be treated by others in ways they do not like to be treated. Yet, we should keep in mind that, for a Kantian, the Dark Rule (i.e., treating others as a means) is intrinsically unethical, hence it is not a universalizable rule.

Having pointed out this unconvincing dimension of Baccarini and Malatesti's account, we wish to next raise objections about forcing $\mathrm{MB}$ on psychopaths even if that was indeed the case.

Involuntary treatment has been justified by combining public reasons of social security (Persson and Savulescu, 2012, 2019) with other criteria implemented in different legislations (Saya et al., 2019), such as mental incapacity and non-intrusiveness of the treatment. Remarkably, all these criteria are now challenged by recent international standards for the rights of persons with disabilities, where informed consent to mental health services has been vigorously supported in any case (see United Nations, 2006, art. 14; United Nations, 2008, par. 64-65; United Nations, 2019).

With regard to $\mathrm{MB}$ of psychopaths, it is questionable that these criteria can be met.

In most cases, it is doubtful to claim that the psychopath's volition is harmed. Remarkably, psychopaths are multifaceted in decision-making, by mainly lacking emotional engagement in moral choice/action while their rational judgment is unimpaired (Cima et al., 2010; Aharoni et al., 2014; Jurjako and Malatesti, 2016). Evolutionists do not see psychopathic traits as expression of an underlying dysfunction, but as a persisting adaptation to certain environments (Glenn et al., 2011). Notably, there are still discrepancies between the PCL-R construct of psychopathy and the corresponding official category of antisocial personality disorder (ASPD) in the DSM (Few et al., 2015). These considerations together could reinforce the argument that we are not totally entitled to classify psychopathy as a proper mental incapacitation. It must be noticed that PCL-R diagnoses are over-inclusive, since the scale attributes psychopathic traits dimensionally to a large group of people, including nonoffending and subclinical individuals such as businessmen, lawyers, actors, politicians, and rebels of various sort, not only serial killers and recidivist offenders (Skeem et al., 2011).

\section{REFERENCES}

Aharoni, E., Sinnott-Armstrong, W., and Kiehl, K. A. (2014). What's wrong? Moral understanding in psychopathic offenders. J. Res. Pers. 53, 175-181. doi: 10.1016/j.jrp.2014.10.002

Baccarini, E., and Malatesti, L. (2017). The moral bioenhancement of psychopaths. J. Med. Ethics 43, 697-701. doi: 10.1136/medethics-2016-103537

Cavell, S. (1990). Conditions Handsome and Unhandsome: The Constitution of Emersonian Perfectionism. Chicago, IL: University of Chicago Press.

Cima, M., Tonnaer, F., and Hauser, M. D. (2010). Psychopaths know right from wrong but don't care. Soc. Cogn. Affect. Neurosci. 5, 59-67. doi: $10.1093 /$ scan/nsp051
Most importantly, $\mathrm{MB}$ is far from being the least restrictive or intrusive treatment. This might exclude most MB means, especially those that are irreversible (e.g., neurosurgeries), impact severely on intertwined functions (e.g., psychotropic drugs, brain stimulations, etc.), and that pass on through generations unpredictably (i.e., gene editing).

Moreover, the call for involuntary treatment is not as neutral and objective as often depicted by its promoters (Garasic, 2013). The "greater good for society" behind the suspension of human rights is often charged with biopolitical values, and it exploits the patient/prisoner as a tool to reinforce or instill specific norms/standards in the society. The defense of coercive MB hides an idea of "moral perfectionism" (Cavell, 1990), according to which we must conform to an idealistic and demanding account of morality where moral imperfections or differences are never tolerated and need to be eliminated. Defining the "morally perfect" is a challenge as much as concluding that a society without moral defects would be a better society. What is the prototypical "moral individual" into whom we should transform the psychopath?

This approach creates substantial frictions with the individual rights. For its moral specificity, coercive $\mathrm{MB}$ interferes tremendously with individual autonomy and freedom without empowering moral competence (Harris, 2011, 2016; Corbellini and Sirgiovanni, 2015). Personal preferences/options belong to a larger spectrum of moral acceptability than that conventionally prescribed by society in a given historical time.

Furthermore, it is unclear whether we should prescribe mandatory $\mathrm{MB}$ also to non-psychopathic offenders and preventively to non-offending or subclinical psychopaths. The same reasons of social security, in fact, seem to predispose ourselves (and society) to large extensions of the legitimacy of MB.

In conclusion, we defend the view that the right to refuse $\mathrm{MB}$ must be protected. It seems that without consent, psychopathic offenders' incarceration or admission to psychiatric facility are still the only acceptable security measures.

\section{AUTHOR CONTRIBUTIONS}

The authors discussed, reviewed, and approved together the entire manuscript. ES conceived and wrote the first part of the manuscript and half of the second part, MG conceived and wrote the second part.

Corbellini, G., and Sirgiovanni, E. (2015). Against paternalistic views on neuroenhancement: a libertarian evolutionary account. Med. Secoli 27, 1089-1110. doi: 10.1007/s11299-016-0188-1

Curry, O. S. (2016). "Morality as cooperation: a problem-centred approach," in The Evolution of Morality, eds K. Shackelford, and R. D. Hansen (Basel: Springer International Publishing), 27-51. doi: 10.1007/978-3-319-19671-8_2

Decety, J., Chen, C., Harenski, C., and Kiehl, K. A. (2013). An fMRI study of affective perspective taking in individuals with psychopathy: imagining another in pain does not evoke empathy. Front. Hum. Neurosci. 7:489. doi: 10.3389/fnhum.2013.00489

Few, L. R., Lynam, D. R., Maples, J. L., MacKillop, J., and Miller, J. D. (2015). Comparing the utility of DSM-5 section II and III antisocial 
personality disorder diagnostic approaches for capturing psychopathic traits. Pers. Disord. Theor. Res. Treat. 6, 64-74. doi: 10.1037/per00 00096

Garasic, M. D. (2013). The singleton case: enforcing medical treatment to put a person to death. Med. Health Care Philos. 16, 795-806. doi: 10.1007/s11019-013-9462-8

Gaus, G. (1996). Justificatory Liberalism: An Essay on Epistemology and Political Theory. Oxford: Oxford University Press.

Gaus, G. (2011). The Order of Public Reason: a Theory of Freedom and Morality in a Diverse and Bounded World. Cambridge: Cambridge University Press.

Glenn, A. L., Kurzban, R., and Raine, A. (2011). Evolutionary Theory and Psychopathy. Aggress. Violent Behav. 16, 371-380. doi: 10.1016/j.avb.2011.03.009.

Hare, R. (2003). Hare Psychopathy Checklist-Revised (PCL-R), 2nd Edn. Toronto, ON: Multi-Health System.

Harris, J. (2011). Moral enhancement and freedom. Bioethics 25, 102-111. doi: $10.1111 /$ j.1467-8519.2010.01854

Harris, J. (2016). Moral blindness - The gift of the god machine. Neuroethics 9 , 269-273. doi: 10.1007/s12152-016-9272-9

Jurjako, M., and Malatesti, L. (2016). Instrumental rationality in psychopathy: implications from learning tasks. Philos. Psychol. 29, 717-731. doi: 10.1080/09515089.2016.1144876

Paulhus, D. L., and Williams, K. M. (2002). The Dark Triad of personality: narcissism, Machiavellianism and psychopathy. J. Res. Pers. 36, 556-563. doi: 10.1016/S0092-6566(02)00505-6

Persson, I., and Savulescu, J. (2012). Unfit for the Future. Oxford: Oxford University Press.

Persson, I., and Savulescu, J. (2019). The duty to be morally enhanced. Topoi 38, 7-14. doi: 10.1007/s11245-017-9475-7

Saya, A., Brugnoli, C., Piazzi, G., Liberato, D., Di Ciaccia, G., Niolu, C., et al. (2019). Criteria, procedures, and future prospects of involuntary treatment in psychiatry around the world: a narrative review. Front. Psychiatry 10:271 doi: 10.3389 /fpsyt.2019.00271

Skeem, J. L., Polaschek, D. L. L., Patrick, C. J., and Lilienfeld, S. O. (2011). Psychopathic personality: bridging the gap between scientific evidence and public policy. Psychol. Sci. Public Interest 12, 95-162. doi: $10.1177 / 1529100611426706$

United Nations (2006). Convention on the Rights of Persons with Disabilities and Its Optional Protocol. Adopted by UN General Assembly Resolution A/RES/61/106 of 3 December 2006. New York, NY: United Nations. Available online at: https://www.un.org/development/desa/disabilities/convention-onthe-rights-of-persons-with-disabilities.html

United Nations (2008). Torture and Other Cruel, Inhuman or Degrading Treatment or Punishment. Adopted by UN General Assembly Resolution A/63/175 of 28 July 2008. New York, NY: United Nations. Available online at: https://spinternet.ohchr.org/SP/Resolutions/Shared\%20Documents/ RES/A_HRC_RES_8_8_E.pdf.

United Nations (2019). Report of the Special Rapporteur on the Rights of Persons with Disabilities. Adopted by UN General Assembly Resolution A/74/186 of 17 July 2019. New York, NY: United Nations. Available online at: https://www.un. org/ga/search/view_doc.asp?symbol=A/74/186

Conflict of Interest: The authors declare that the research was conducted in the absence of any commercial or financial relationships that could be construed as a potential conflict of interest.

Copyright $(2020$ Sirgiovanni and Garasic. This is an open-access article distributed under the terms of the Creative Commons Attribution License (CC BY). The use, distribution or reproduction in other forums is permitted, provided the original author(s) and the copyright owner(s) are credited and that the original publication in this journal is cited, in accordance with accepted academic practice. No use, distribution or reproduction is permitted which does not comply with these terms. 